\title{
Pemodelan Tsunami Sederhana dengan Menggunakan Persamaan Differensial Parsial
}

\author{
Indriati Retno Palupi*, Wiji Raharjo, Eko Wibowo, Hafiz Hamdalah \\ Geophysical Engineering, UPN "Veteran" Yogyakarta \\ Jl. SWK 104 Condongcatur Sleman, Yogyakarta 55283 \\ "Email: inder13101986@gmail.com
}

\section{ABSTRACT}

One way to solve fluid dynamics problem is using partial differential equation. By using Taylor expansion, fluid dynamics can be applied simply. For the example is tsunami wave. It is include to hyperbolic partial differential equation, tsunami wave propagation can describe in space and time function by using Euler Forward Time Central Space (FTCS) formula.

Keywords: Differential partial equation, Euler FTCS, Tsunami modelling

\section{ABSTRAK}

Salah satu cara untuk menyelesaikan permasalahan yang berhubungan dengan dinamika fluida adalah menggunakan persamaan differensial parsial. Dengan menggunakan pendekatan deret Taylor, proses dinamika fluida dapat dengan mudah diaplikasikan. Salah satu contoh dari permasalahan tersebut adalah gelombang tsunami. Termasuk kedalam golongan persamaan differensial parsial hiperbolik, penyebaran gelombang tsunami dapat digambarkan berdasarkan fungsi ruang dan waktu dengan menggunakan formula Euler Forward Time Central Space (FTCS).

Kata Kunci: Persamaan differensial parsial, Euler FTCS, modelling tsunami.

\section{PENDAHULUAN}

Letak Indonesia yang berada pada tiga batas lempeng tektonik utama menjadikan Indonesia rawan akan bencana baik itu gempa bumi, letusan gunungapi dan tsunami. Ketiga lempeng tersebut adalah lempang Australia di sebelah selatan yang bergerak ke arah utara, lempeng Samudera Pasifik di sebelah timur yang bergerak ke arah relatif barat laut, Lempeng Eurasia yang relatif diam di sebelah utara dan lempeng Filipina yang bergerak ke arah relatif barat laut seperti ditunjukkan pada Gambar $1^{[1]}$.

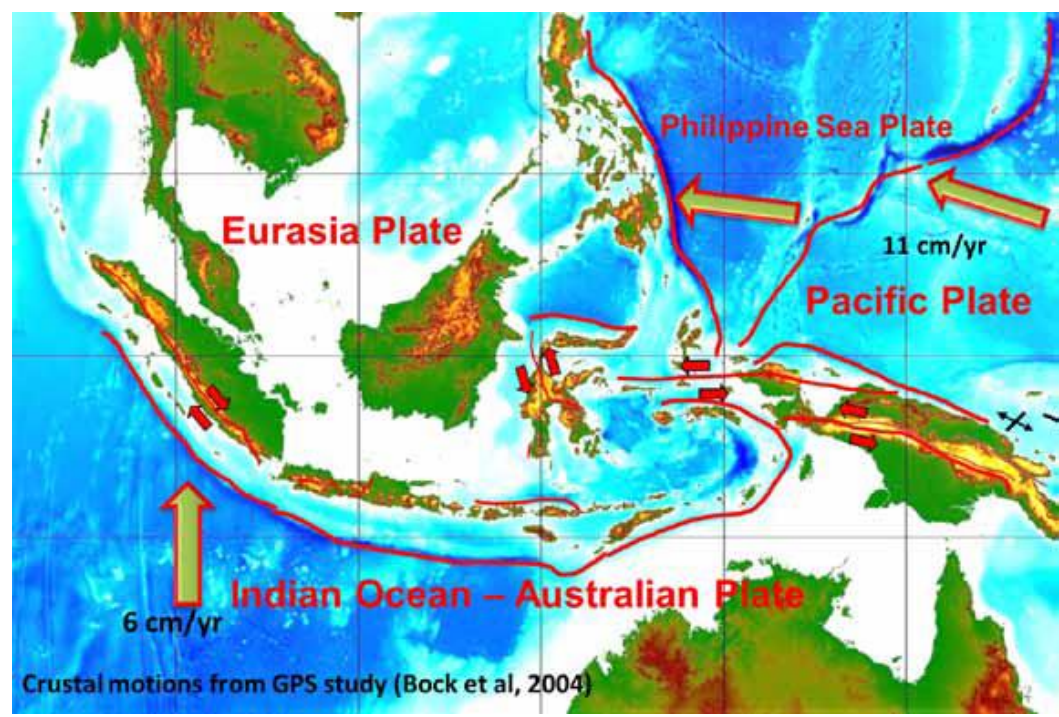

Gambar 1. (Color Online) Pergerakan lempeng di sekitar Indonesia ${ }^{[1]}$ 
Sesuai dengan teori bingkas elastik, bahwa saat tekanan/gaya yang mengenai batuan melewati daya elastisitas batuan tersebut, maka akan terjadi patahan pada batuan. Patahan tersebut dapat menimbulkan fenomena gempa bumi tektonik. Jika gempa bumi tektonik ini terjadi di laut, maka dapat menyebabkan bencana tsunami.

Tsunami sendiri berasal dari Bahasa Jepang yaitu tsu yang berarti pelabuhan dan nami yang berarti gelombang. Kata ini kemudian diartikan gelombang besar yang menghantam pantai. Pada umumnya tsunami terjadi akibat gempa bumi tektonik besar dengan pusat gempa dangkal $(<70 \mathrm{~km})^{[2]}$. Selain itu, mekanisme sumber gempa merupakan pergerakan lempeng tektonik secara vertikal ${ }^{[1]}$. Ilustrasi dari gempa bumi tektonik penyebab tsunami dapat dilihat pada Gambar 2.

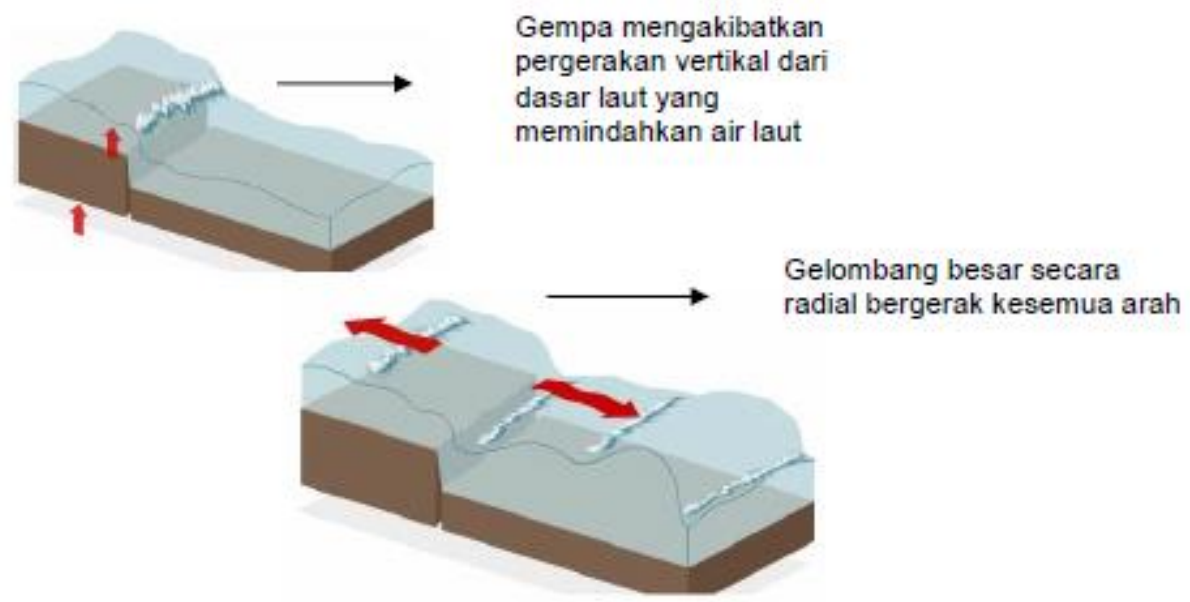

Gambar 2. (Color Online) Ilustrasi terjadinya tsunami ${ }^{[2]}$

Di Indonesia sendiri tercatat 10 bencana tsunami dalam kurun waktu 25 tahun terakhir, yaitu di Flores (12 Desember 1992), Banyuwangi (1994), Biak (1996), Maluku (1998), Banggai, Sulawesi Utara (2000), Ransiki, Papua Barat (2002), Aceh (Desember 2004), Nias (2005), Jawa Barat (2006), Bengkulu (2007) dan Mentawai (2010) ${ }^{[1]}$.

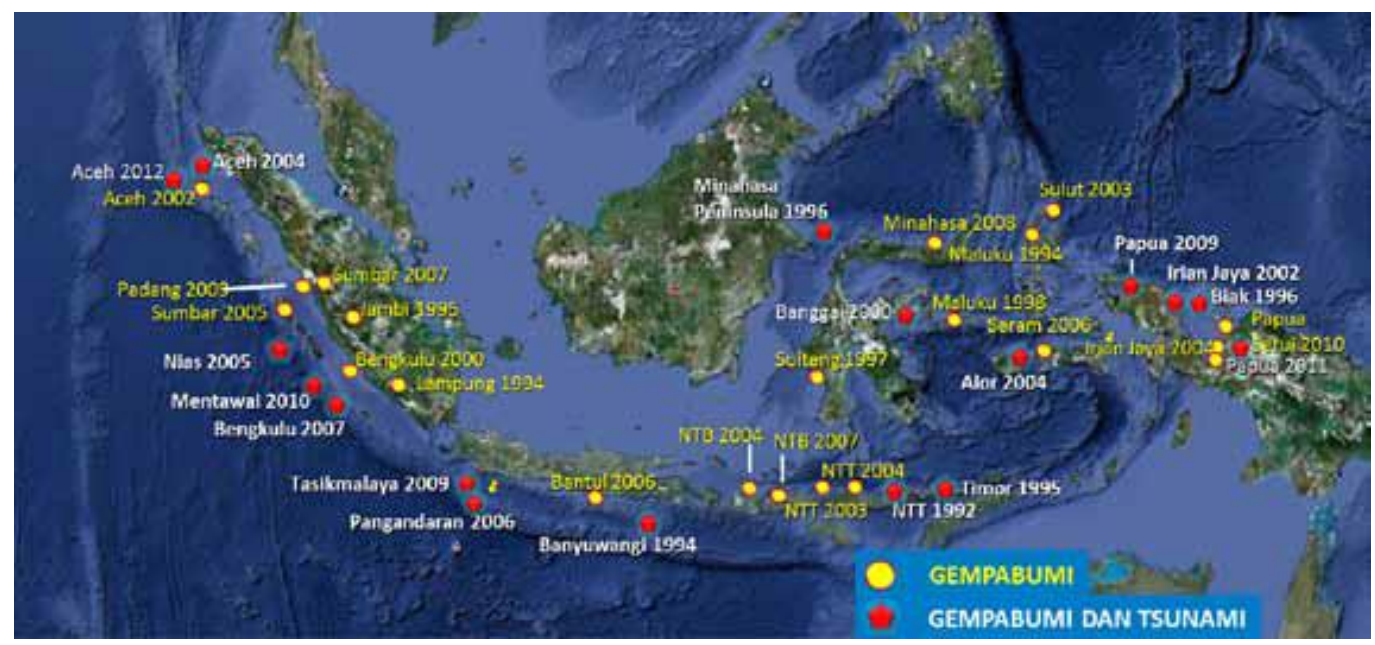

Gambar 3. (Color Online) Sebaran gempa bumi dan tsunami di Indonesia ${ }^{[1]}$. 


\section{METODE}

Persamaan differensial parsial merupakan salah satu solusi untuk memecahkan permasalahan baik yang linier maupun non linier. Pada permsalahan linier, antara variabel bebas dan turunannya berhubungan secara linier dan dapat dihasilkan solusi tunggal. Sementara pada permasalahan non linier dapat dihasilkan lebih dari satu solusi [3]. Persamaan differensial parsial dengan sederhana dapat diturunkan melalui deret Taylor yaitu sebagai berikut :

$$
\begin{aligned}
& f(x+\Delta x)=f(x)+\frac{\partial f}{\partial x} \frac{\Delta x}{1 !}+\frac{\partial^{2} f}{\partial x^{2}} \frac{\Delta x^{2}}{2 !}+\frac{\partial^{3} f}{\partial x^{3}} \frac{\Delta x^{3}}{3 !}+\cdots \\
& f(x-\Delta x)=f(x)-\frac{\partial f}{\partial x} \frac{\Delta x}{1 !}+\frac{\partial^{2} f}{\partial x^{2}} \frac{\Delta x^{2}}{2 !}-\frac{\partial^{3} f}{\partial x^{3}} \frac{\Delta x^{3}}{3 !}+\cdots
\end{aligned}
$$

Aplikasi dari deret Taylor adalah untuk memecahkan permasalahan yang jika digambarkan ke dalam bentuk kurva sebagai berikut :

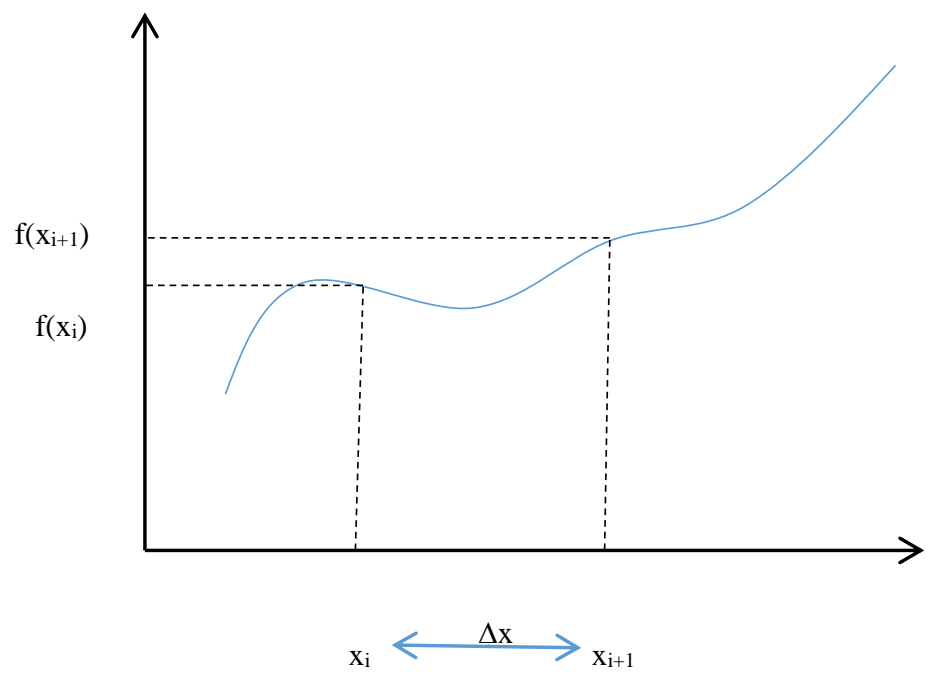

Gambar 4. (Color Online) Sketsa kurva

Berdasarkan Gambar 4 diketahui bahwa $x_{i+1}=x_{i}+\Delta x$ dan $f\left(x_{i+1}\right)=f\left(x_{i}+\Delta x\right)$. Untuk memecahkan solusi dari persamaan differensial orde pertama, terdapat tiga metode yaitu dengan menggunakan forward space, central space, maupun backward space.

$$
\begin{aligned}
& \frac{\partial f}{\partial x}=\frac{f(x+\Delta x)-f(x)}{\Delta x}=\frac{f\left(x_{i+1}\right)-f\left(x_{i}\right)}{\Delta x} \\
& \frac{\partial f}{\partial x}=\frac{f(x+\Delta x)-f(x-\Delta x)}{2 \Delta x}=\frac{f\left(x_{i+1}\right)-f\left(x_{i-1}\right)}{2 \Delta x} \\
& \frac{\partial f}{\partial x}=\frac{f(x)-f(x-\Delta x)}{\Delta x}=\frac{f\left(x_{i}\right)-f\left(x_{i-1}\right)}{\Delta x}
\end{aligned}
$$

Persamaan (3), (4) dan (5) berturut-turut adalah bentuk penyelesaian persamaan differensial orde pertama dengan menggunakan forward space, central space dan backward space. Sedangkan untuk memecahkan solusi persamaan differensial orde kedua digunakan hanya metode central space ${ }^{[3]}$.

$$
\frac{\partial^{2} f}{\partial x^{2}}=\frac{f(x+\Delta x)-2 f(x)+f(x-\Delta x)}{\Delta x^{2}}=\frac{f\left(x_{i+1}\right)-2 f\left(x_{i}\right)+f\left(x_{i-1}\right)}{\Delta x^{2}}
$$

Berdasarkan penelitian yang dilakukan oleh Shaw dan Chakraverty tahun 2014, pemodelan tsunami dilakukan dengan menggunakan persamaan diferensial hiperbolik berdasarkan persamaan Navier Stokes. Pemodelan tsunami dapat dilakukan dengan dua metode yaitu 
dengan metode beda hingga (finite difference methode, (FDM)) dan metode finite volum (finite volume method, (FVM)). Papper ini hanya fokus pada pemodelan dengan FDM yang menghubungkan fungsi waktu dan spasial ${ }^{[4]}$.

Persamaan differensial parsial hiperbolik disebut juga sebagai persamaan adveksi. Memiliki persamaan yang simpel sebagai berikut ${ }^{[5]}$ :

$$
\frac{\partial f}{\partial t}+v \frac{\partial f}{\partial x}=0
$$

Persamaan (7) merupakan contoh persamaan differensial parsial parabolik untuk 1 Dimensi yang menghubungkan fungsi waktu $(\mathrm{t})$ dan spasial $(\mathrm{x})$ dengan $\mathrm{v}$ sebagai konstanta persamaan. Metode paling mudah yang digunakan untuk menyelesaikan persamaan (7) adalah Euler FTCS (Forward Time Central Space) ${ }^{[3]}$ :

$$
\frac{f_{i}^{n+1}-f_{i}^{n}}{\Delta t}=-v \frac{f_{i+1}^{n}-f_{i}^{n}}{2 \Delta x}
$$

Selain dengan metode Euler FTCS, pemodelan tsunami juga dilakukan oleh Imamura dengan menggunakan metode upwind yang hampir mirip dengan metode Euler FTCS ${ }^{[6]}$.

Dutykh dalam penelitiannya menyebutkan bahwa keberlangsungan tsunami terdiri dari tiga tahap yaitu sumber pembangkit tsunami, penjalaran dan penggenangan. Bagian yang tersulit adalah penggenangan ${ }^{[7]}$. Hal ini terutama pada saat memodelkan bagaimana gelombang tersebut hancur pada saat mencapai batas pinggir pantai karena berhubungan dengan bathymetri dan tipe coastline nya. Sedangkan untuk bagian penjalaran hanya berhubungan dengan permasalahan gelombang tsunami yang terkadang melibatkan berbagai macam asumsi di dalamnya.

\section{HASIL DAN PEMBAHASAN}

Pemodelan tsunami pada papper ini merupakan pemodelan sederhana dengan menggunakan persamaan differensial parsial hiperbolik metode Euler FTCS dan belum memperhitungkan faktor bathymetri dan tipe coastline nya. Persamaan gelombang yang dipilih adalah persamaan gelombang sinusiodal hiperbolik berdasarkan Shaw dan Chakraverty dengan sedikit modifikasi ${ }^{[4]}$. Pemodelan dilakukan dengan menggunakan bahasa pemograman Matlab baik untuk tampilan 1-D maupun 2-D sebagai berikut :

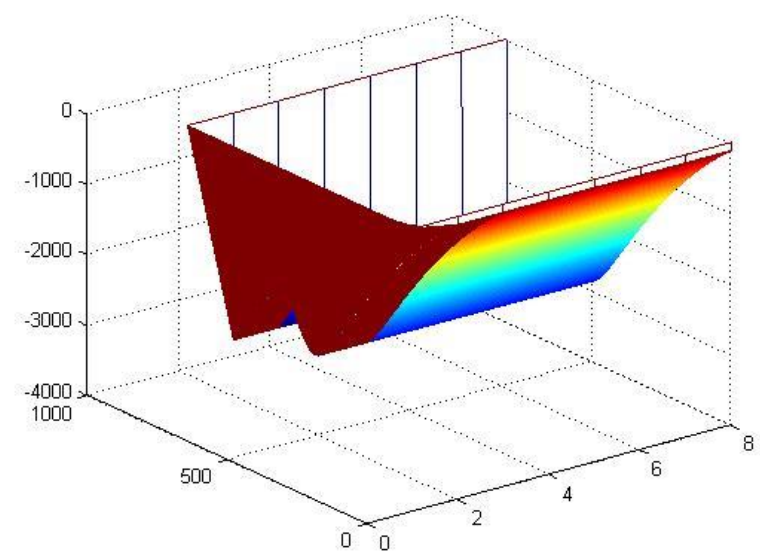

Gambar 5. (Color Online) Model gelombang tsunami 1-D berdasarkan Shaw dan Chakraverty dengan sedikit modifikasi $^{[4]}$ 


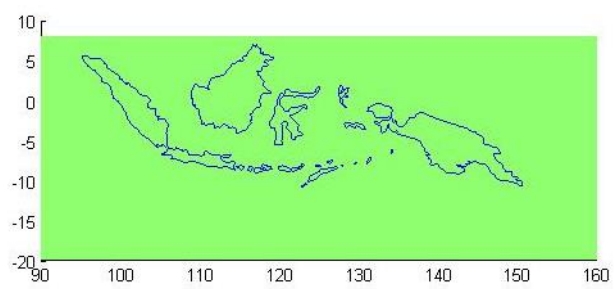

(a)

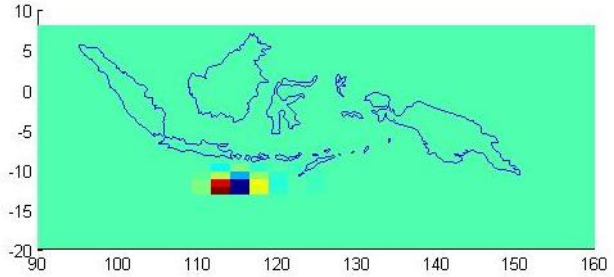

(b)

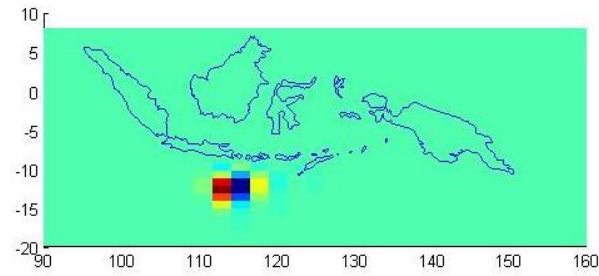

(c)

Gambar 6. (Color Online) Model penyebaran gelombang tsunami dari waktu ke waktu (a) sampai dengan (c) berdasarkan Shaw dan Chakraverty dengan sedikit modifikasi ${ }^{[4]}$

Warna pada Gambar 5 dan Gambar 6 merupakan tinggi gelombang tsunami dimana warna merah mempunyai nilai tertinggi dan biru mempunyai nilai terendah. Pada Gambar 6 diasumsikan terjadi tsunami di selatan Jawa dan dapat dilihat bagaimana persebaran dari gelombang tsunami tersebut sampai dengan batas waktu yang telah ditentukan. Dengan memperlebar batasan spasial dan memperpanjang durasi waktu, dapat dilihat persebaran gelombang dengan lebih luas lagi.

Berdasarkan Gambar 5 dan Gambar 6 pula, dapat diketahui bahwa salah satu manfaat dari persamaan differensial parsial adalah dapat menggambarkan persebaran dari dinamika fluida baik dari segi ruang maupun waktu. Selain dapat bermanfaat untuk menunjang ilmu pengetahuan yang berbasis komputasi, juga dapat diaplikasikan dalam dunia mitigasi bencana.

\section{KESIMPULAN}

Permasalahan yang berhubungan dengan proses dinamika fluida dapat digambarkan dengan mudah menggunakan persamaan differensial parsial, salah satunya adalah persamaan differensial parsial hiperbolik. Penyebaran gelombang tsunami secara sederhana baik untuk tampilan 1-D dan 2-D dapat digambarkan baik dari segi ruang maupun waktu. Hal ini bermanfaat dalam proses mitigasi bencana terlebih lagi jika ditambahkan dengan faktor geologi seperti kondisi bathymetri dan tepi coastline nya. 


\section{DAFTAR PUSTAKA}

1 InaTEWS BMKG, 2012. Pedoman Pelayanan Peringatan Dini Tsunami. Jakarta: BMKG.

2 Ilyas, T. 2006. Mitigasi Gempa dan Tsunami Daerah Perkotaan. Seminar Bidang Kerekayasaan. Fatek-Unsrat, 1-23.

3 Hoffmann, K. A. 1993. Computational Fluid Dynamics for Engineers. The University of Texas at Austria.

4 Shaw, H. S. \& Chakraverty, S. 2014. Numerical Modelling Tsunami Wave Equation. Thesis, Department of Mathematics Nit Rourkela, Rourkela-769 008.

5 Rezolla, L. 2011. Numerical Methods for the Solution of Partial Differential Equation. Albert-Einstei Institute, Max-Planck-Institiute for Gravitational Physics, Postdam, Germany.

6 Imamura, F., Yalciner, A. C. \& Ozyurt G. 2006. Tsunami Modelling Manual (Tsunami Model). Tohoku University and Middle East Technical Unviersity

7 Dutykh, D. 2008. Mathematical Modelling of Tsunami Waves. HAL archives-ouvertes. Centre de Math'ematiques et de Leurs Applications ENS CACHAN/CNRS/UMR 8536. France. 